\title{
Designing Virtual Learning Centers ${ }^{1}$

\author{
Dr Gilbert Paquette \\ LICEF Research Centre, Télé-université \\ Montreal, Quebec, Canada \\ gpaquett@licef.teluq.uquebec.ca
}

\begin{abstract}
Virtual universities and work-place virtual institutes are seen, more and more, as a solution to the huge education demand of the knowledge society. I will limit my subject here to the design of Virtual Learning Centers, seen as the pedagogical heart of a virtual educational institution. This is where courses or learning events are designed, constructed and delivered using the Internet and its many communication possibilities.
\end{abstract}

Many models are available for these learning events. High-tech classrooms, distributed classrooms, multimedia individual instruction, on-line teaching, communities of practice and performance support systems, are now available delivery models. They can be integrated in the same course or in different courses in a flexible, open and inter-operable way within a training organization. We will compare the main features of these models and present a computer-based architecture that can support them in an integrated way.

The choice of a certain combination of delivery models is determined by decisions based on instructional models and strategies. Such strategies have major consequences on the selection of resources for information processing, collaboration, assistance and management of the learning activities. We will present here a general strategy and some aspects of a method for the instructional engineering of distributed learning system.

\section{Introduction}

Distance education, or as I now prefer to say, distributed learning has finally acquired general support from most circles. More than a hundred countries have built distance universities. Most campus universities are developing distance education units or courses. All major companies are building training Intranets for their personnel. In Quebec, the Teccart institute launched its first distance classes in electronics more than fifty years ago and twentyeight years ago, Télé-université became the first Canadian university operating completely at a distance and also the first in the francophone world. Télé-université was created shortly after United Kingdom's Open University, in 1972. Most of its students (90\%) are adult learners in the workplace. This of course, will color a bit what I will present here. But since I have also been a campus professor for ten years, I hope to be general enough.

At the dawn of XXIst century, distributed learning appears to be and indispensable solution to the exponential growth of information in the knowledge society and the new learning activities it forces on individual and organizations. The extremely rapid implementation of the Internet accelerates this movement. The concept of a virtual learning center, resting on the networking of actors and resources much more diversified than in the past, aims to provide access to learners, synchronously or asynchronously, to different resources: instructors and tutors, subject-matter experts, training managers and professors acting as designers.

LICEF, which I have founded in 1992, is Télé-université's research center. Right from the start, the many dimensions of a Virtual Campus have become LICEF's unifying research orientation. [Paquette, 1995] The first research efforts provided insights on specific applications of multimedia telecommunications in distance learning, such as prototyping knowledge-based virtual classroom activities using an hypermedia environment [Paquette \& al., 1993], analysing discourse and interaction in asynchronous teleconferencing [Ricciardi-Rigault et al., 1994] and studying ways to access distributed multimedia databases [Bourdeau \& al., 1993].

From 1992 to 1995, we were involved with six companies and two other research centres, in the Telecom Multimedia project, funded by the Technology Development Fund of the Government of Quebec [Paquette et al,

\footnotetext{
${ }^{1}$ This article is an extended version of a key-note presentation at the Ed-Media 2000 conference.
} 
1995, 1996]. Some of the partners were involved in the development an ATM platform allowing multipoint multimedia communications. Our part was to help building an architecture and some distance learning tools and courses for this platform, serving as building blocks for a virtual campus. This project has enabled us to build a first conceptual architecture. A first support environment, called the HyperGuide, was also developed, tested and delivered. This environment has demonstrated the feasibility of the concepts presented here, since it has been used by hundred of students at Télé-université in a real life context, in one of the university's regular programs.

From 1995 to 1998, we were mainly funded by the Quebec Information Highway Fund², to develop the HyperGuide model into a fully working virtual campus environment. In this project, we have built a Virtual Learning Center (VLC) model and architecture, which is the central part of a Virtual Campus. We have also built advanced prototypes of the VLC model. Finally, we have build a new version of our instructional engineering methodology (MISA) based on previous work we had done on the AGD Didactical Engineering Worbench [Paquette et al, 1994].

To build the advanced prototypes, we re-engineered a course in economics using the MISA methodology. The intended goal was to facilitate collaborative learning by using content that had modular qualities. The metaphor was that of a virtual seminar. In both cases, students had the necessary tools to accomplish some research on a subject, then engage in team production of papers that were then presented to the group within the virtual conference. Various mechanisms were implemented to allow on-line access to multimedia documents and communication with other learners and tutors. The second environment was much richer than the first [De la Teja et al, 1998]. Many media could be integrated into the learners productions. A video server was in use. Tools for self-management, group management and production tools were also included. Finally, a full network support was provided for desktop video conferencing and white board facilities, as well as asynchronous teleconferencing. This last seven week experiment has proven the feasibility of heterogeneous networking in a VLC. A group of 15 students an tutor, some using cable-modem, ADSL or ATM networking, were able to do various collaborative learning activities together.

To build the VLC model, we have used object oriented modeling techniques. Jacobson's use cases methodology [Jacobson I., 1993] has helped us achieve needs specification. Use cases are sets of actions that an actor can do while interacting within a system. Five actors were then identified within a VLC: learners, trainers, content experts, designers and managers. Sixty-three roles have been defineds for these actors, each one being a set of use cases. Table 1 presents some of these roles. Then, for some of these roles, we have build object oriented graphs using the OMT methodology [Rumbaugh et al, 1992]. From these graphs, we were able to design or reuse tools to be integrated in a VLC.

In 1997, the Virtual Campus has become a powerful integrative concept at Télé-université. An ambitious five-year plan was supported by the Ministry of Education to transform the 23-year old distance university into a virtual campus based on a merge of knowledge-based, hypermedia and telecommunications technologies. At the same time we had decided to re-implement the VLC architecture on a web-based platform. In 1999, we had achieved the actual Explor@ implementation of the VLC and we have started using it to develop and deliver telelearning courses and environments. There is now a growing number of courses at Télé-université using the Explor@ platform. Also some university and workplace implementation have started outside Télé-université, at Hydro-Québec, in three professional corporations and in the SavoirNet project aiming to provide and advanced platform for universities and college course, joining television and internet technologies. With the support of Bell Canada, a new R\&D effort has started on on new version of the Explor@ platform, while courses are being developed using the actual system.

In this chapter of the book, we will strart the discussion of Virtual Learning Centers within an organization by first reviewing the main delivery models in distributed education in order to establish some orientation principles. Then, we will present LICEF's model of the VLC, its actors and their functions, the process in which they participate and the roles they play, as well as the virtual spaces where they evolve. Finally, we will present a general strategy and some aspects of a method for the instructional engineering of distributed learning events within a Virtual Learning Center.

\footnotetext{
${ }^{2}$ Part of the work was also funded through our participation in the TeleLearning Network of Centers of Excellence (TL-NCE),
} financed by Industry Canada, of which we are one of the three founding members. 


\begin{tabular}{|c|c|}
\hline ACTOR AND MAIN FUNCTION & ROLES OR CORRESPONDING SUB-PROCESSES \\
\hline \begin{tabular}{|l|} 
LEARNER \\
(Transforms information into \\
knowledge)
\end{tabular} & $\begin{array}{l}\text { Navigator in the learning scenario } \\
\text { Explorer of documentation sources } \\
\text { Explorer of external databases } \\
\text { Problem solver } \\
\text { Contractor in a project } \\
\text { Producer of assessed activities } \\
\text { Self-evaluator of his activities } \\
\text { Social actor } \\
\text { Debater in a telediscussion } \\
\text { Communicator }\end{array}$ \\
\hline \begin{tabular}{|l} 
TRAINER \\
(Facilitates learning)
\end{tabular} & $\begin{array}{l}\text { Diagnostic producer } \\
\text { Advisor } \\
\text { Evaluator of learners productions } \\
\text { Helper in using the environment } \\
\text { Team and group animator } \\
\text { Coach }\end{array}$ \\
\hline \begin{tabular}{|l|} 
DESIGNER \\
(Builds, adapts and maintains a \\
learning system)
\end{tabular} & $\begin{array}{l}\text { Training needs analyst } \\
\text { Knowledge model builder } \\
\text { Pedagogical scenario builder } \\
\text { Writer of learning systems plans and cost estimates } \\
\text { Delivery planner } \\
\text { Producer of learning materials } \\
\text { Designer of the system’s development plan } \\
\text { Media Producer }\end{array}$ \\
\hline $\begin{array}{l}\text { MANAGER } \\
\text { (Manages actors and events) }\end{array}$ & $\begin{array}{l}\text { Decision maker } \\
\text { Controller } \\
\text { Director of delivery operations } \\
\text { Team and group setup organizer } \\
\text { Experimentation and validation organizer } \\
\text { Learning assessment coordinator } \\
\text { Learning system assessment director } \\
\text { Network manager }\end{array}$ \\
\hline $\begin{array}{l}\text { INFORMER } \\
\text { (Makes information available) }\end{array}$ & $\begin{array}{l}\text { Information presenter } \\
\text { Content clarification expert } \\
\text { Manager of mediated knowledge } \\
\text { Trace analyzer } \\
\text { Documents analyzer }\end{array}$ \\
\hline
\end{tabular}

Table 1 - Actors and roles in a Virtual Learning Center 


\section{Distributed Models for a VLC}

At the beginning of this new millenium, some megatrends are prevalent. The exponential growth of information and the management of knowledge, the ubiquity of networked and media integration, the new needs for higher-order skills and new collaborative learning paradigms all lead to some form of telelearning or distributed learning. Behind terms like "distance education", "on-line learning", "telelearning” and "multimedia training", is a multi-facetted reality from which we can identify many delivery models.

\section{Distributed Education Models}

Behind this diversity, we will try to find unity through pedagogical, as well as technological integration. Let us first consider six of these models.

"High-tech" Classooms group students and trainers in a single location, together with sophisticated multimedia and network equipment. Networked computers can give access to web sites, internet multimedia presentation as well as video-conferencing with the outside world. Many universities and organizations build electronic campuses on this model, to help manage the many possible transitions from a predominant classroom presentation model to more interactive and flexible ways to learn and teach..

Distributed Classrooms are quite similar, close to the fact that learners and trainers are in two or more distant locations. Learning events use generally specialized, and sometimes costly, real-time videoconferencing system. Alternatively, a desktop multi-point videoconferencing software can be used. Both of these first two models are close to traditional classroom teaching, some would say with more hype but not many pedagogical gain.

Hypermedia self-training on the Web or CD-ROM give preference to an individualized learning approach to Education. In the "pure" model, there is neither trainer nor collaboration between learners in the system. A training manager supplies learning resources: self-training modules, interactive or passive Web sites, multimedia material on CD-ROM or DVD. The main benefit of this model is to enable the learner to progress at her own pace, wherever she is and whenever she chooses.

Asynchronous "on line" training departs from this individualistic view. It is organized and led by a trainer or a teacher, priming interaction with the learners or between learners for team work and discussion groups [Harasim 1990; Hiltz, 1990]. Unlike the above classroom like models, these interactions are asynchronous, retaining some of the flexibility of self-training, with the exception that the pace between modules is decided upon by the teacher/trainer. The main tools and activities are forums, email, FTP transfer, together with less frequent audio or videoconferencing, on-line presentations and real-time collaborative activities.

Communities of Practice focus on a professional task [Ricciardi-Rigault et al, 1994]. The learners are basically content expert trying to extend their knowledge through the asynchronous exchange of information via forums, email, or document transfer. They progress through team problem solving and know-how sharing around projects. Unlike the previous model, there is no trainer acting as a content expert or pedagogical coach, but a group animator that possesses less knowledge in the subject matter than the learners, but more knowledge of methods to support group interaction.

Performance Support Systems integrate training even more closely to the actual work process and tasks in an organization [Gery, 1997]. Extensive use of the organization's data banks and support software are made both ways: to use training material to help job performance and also to use real problems and tools to support training at and outside the job. On-line help, advisor systems, human supervisors are supporting these training-working activities. This model promotes just-in-time information to help the user focus, alone or in teams, on real-life situated problems.

Each of these models has advantages and drawbacks. The first two are very popular at the present time. They rest on the traditional paradigm inherent in live information transmission where a teacher uses computerized and audiovisual equipment to animate a real-time multimedia group presentation, broadcast locally or to several distant locations where learners are gathered. This model sometimes requires costly equipment as well as the learners and teacher's physical presence simultaneously. Moreover, too often it reduces the learners' interaction and initiative to a level that is in no way better than that of a course presentation in an auditorium. 
In the "hypermedia self-training" model and its web-based applications, the main advantage is in the individualization of training. The lack of a collaborative dimension disappears if we combine it with some form of "on-line training" or "community of practice" where the computer is used mainly as a communication and an information access tool, rather than a media. Finally, the EPSS approach favors two important principles : just-intime information triggered by the problem solving activity and learning seen as information processing. The learning scenario concept at the heart of our proposal is based on these principles.

\section{A new paradigm for Education}

We need to meet the growing education needs in a social-economic context where lifelong learning, sought by busy and mobile people, involves cognitive abilities of a much higher level than what was required in the past. As pointed out by a recent report produced by Quebec's Higher Council for Education :

“ From now on, the emphasis must bear on higher cognitive abilities (reasoning, problem solving, planning) and social abilities (autonomy, communication and collaboration). These are consistent with the capabilities expected from workers following the impacts of information and communication technology on the very nature of work ". ${ }^{3}$

We clearly face an education paradigm shift. The availability of Internet and multimedia technologies exposes the learner to numerous sources of information among which he must make choices. Figure 1 present this paradigm shift: from a teacher, sole source of expertise intended for many learners, to a learner-centered situation where each learner is in contact with many sources of information and expertise. Especially on the web, the richness of information has advantages, but it submits the learner to many useless or false sources of information that he/she must evaluate, select and adapt.

This changes the focus of the instructor's role from an information provider to a facilitator pointing to many sources of information, helping learner selecting and processing information, proposing interesting tasks, problems or projects, coaching the learners to achieve meaningful production and knowledge building.

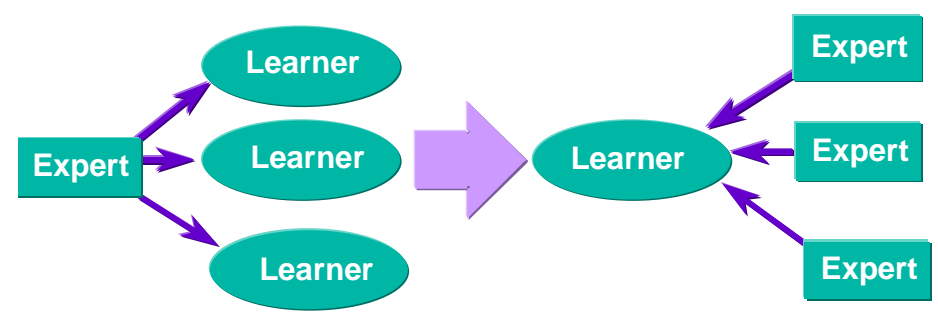

Figure 1 - Paradigm shift

\section{Principles for the design of Virtual Learning Centers}

This new educational paradigm and the study of these different distributed learning models suggest ten principles that should guide the implementation of virtual learning centers as a learning system.

1. A learning system is centered on the learner. The other actors, trainers, managers, informers and designers, have roles defined according to the learners activities.

2. A learning system fully uses the distance as an asset to facilitate lifelong learning. It must be available whenever and wherever the learner may pursue his learning process.

3. A learning system proposes a constructivist pedagogy by bringing forward the learner's self-activity in building his own knowledge, by taking into account his characteristics and by helping him integrate available information, within a context and use, in other words, by helping him transform information into knowledge.

3 Annual Report 1993-94 of the Conseil supérieur de l'éducation, Gouvernement du Québec, p. 24 (free translation by the author). 
4. A learning system is process-oriented in the sense that the learner builds his knowledge by solving problems, by accomplishing tasks and realizing projects.

5. A learning system offers just-in-time information by making information available at the moment it is necessary for a problem-solving activity.

6. A learning system must induce the development of knowledge and skills that will make learners capable to search, find and process information adequately; it must facilitate the development of transfer abilities as well as a high level of autonomy in the learning process.

7. A learning system aims to develop social skills and positive attitudes towards learning.

8. A learning system offers the different actors various ways of accessing and processing information, such as software environments available for information search and communication, for process-related advice, for collaboration among learners as well as between learners and facilitators of the learning process.

9. A learning system supports the learning process through various seamlessly integrated resources, tools and documents within a coherent set of objectives, tools and methods.

10. A learning system is open, that is to say it can be adapted by learners or trainers to the particular needs of learners, teams or groups of learners from different surroundings or cultures; it is modular in order to facilitate its adaptation, updating or its re-engineering.

\section{The Virtual Learning Center Model}

Would it not be interesting to support any mixture of all the different delivery models we have presented in section 1 ? Based on the above principles, we will now present a model of a virtual learning center that aims to do just that, especially to integrate the best features of the last four models.

\section{Actors in a Virtual Learning Center}

In our Virtual Learning Center architecture, we have identify five types of actors, an approach that is now embedded into some other delivery systems. Each actor is personified by different persons or media agents playing a variety of roles and relying on a variety of resources, documents, communication and production tools.

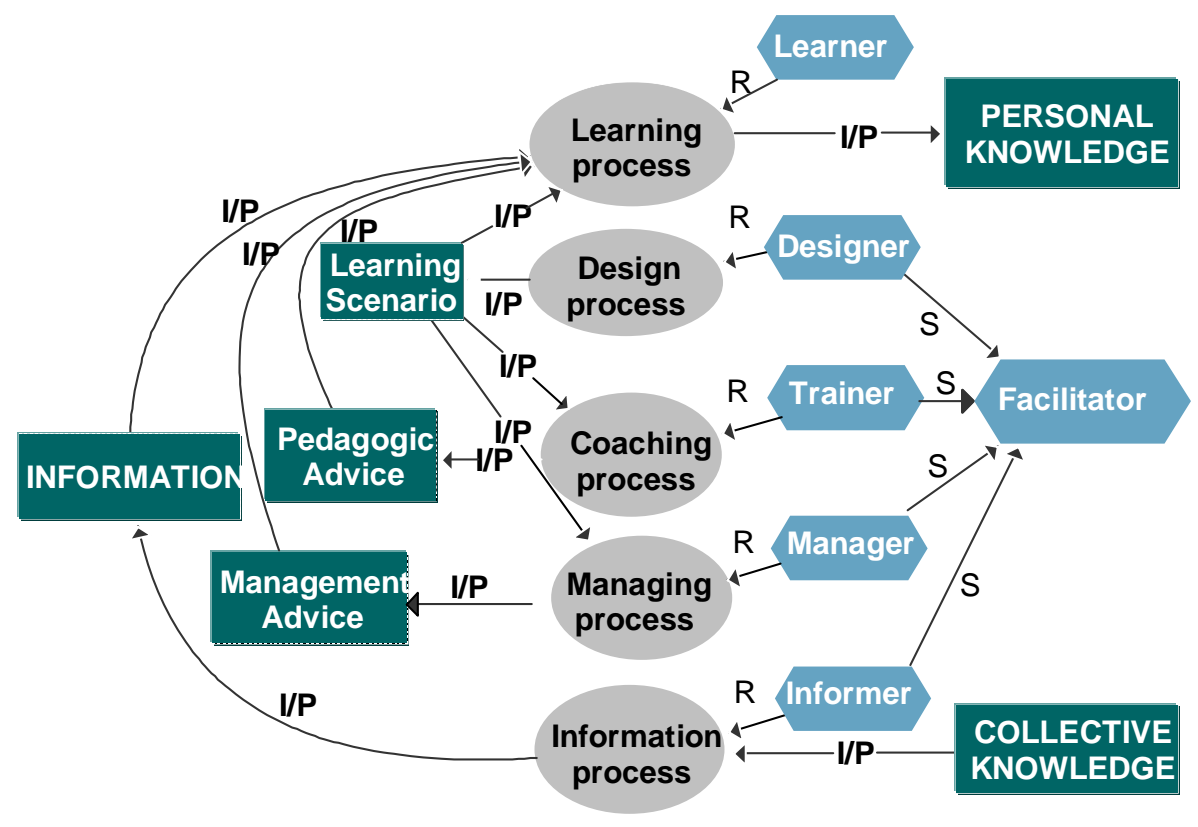

Figure 2 - Actors and main telelearning process 
Figure 2 present the main interactions between these actors. There is first a basic cycle where an Informer, ruling ${ }^{4}$ the information process, process the collective knowledge domains to provide new information to the learner. The learner, ruling learning process, transform this information into personal knowledge. The other three actors, acting as facilitators, support this basic process in different ways. The Designer construct the learning environment, in particular the learning scenarios. The Trainer is pedagogical advisor, mainly coaching the learner according to the learning scenarios. The Manager, organizes groups and events with respect to the learning scenarios and is also an advisor on organization issues. The possible roles of these actors have been presented in table 1 . Here is a definition of their main function.

- The Learner's main function is to transform information into personal knowledge. The learner achieves knowledge acquisition and construction by managing a learning environment planned by another actor, the designer, through collaboration with other learner agents and assistance from other actors.

- The Informer makes information available to the learner. The corresponding content agents may be persons providing information, but also books, videos, courseware, etc. The learner can also produce information available to others as a result of his/her production activities, thus producing an informer agent.

- The Designer is the actor planning, adapting and sustaining a telelearning system that integrates information sources (human informers or learning materials), and also self-management, assistance and collaboration tools for the other actors.

- The Trainer provides pedagogical assistance or coaching by giving advice to the learner about her individual process and the interactions that may be useful to her based on the learning scenarios defined by the designer.

- Finally, the Manager provides organizational assistance to the learner (and other actors) by managing actors and events, creating groups or making teleservices available in order to insure the success of the learning process, based on the scenarios defined by the designer.

At delivery time, these actors interact each within their own computer-based environment distributed through the Virtual Learning Center (VLC). The Explor@ implementation of a VLC [Girard et al, 1999] is a web-based system built on this conceptual framework that helps designers build a learning environment for each actor (including themselves), so they can play their role in programs, courses or learning events. Table 2 presents the main roles of each actor within the delivery models presented in section 1.

\begin{tabular}{|l|l|l|l|l|l|}
\hline & \multicolumn{1}{|c|}{ Learner } & \multicolumn{1}{|c|}{ Informer } & \multicolumn{1}{c|}{ Trainer } & \multicolumn{1}{c|}{ Manager } & \multicolumn{1}{c|}{ Designer } \\
\hline $\begin{array}{l}\text { High-tech } \\
\text { Classroom }\end{array}$ & $\begin{array}{l}\text { Getting presentations, } \\
\text { doing exercice }\end{array}$ & $\begin{array}{l}\text { Teacher presenting } \\
\text { information }\end{array}$ & $\begin{array}{l}\text { Teacher giving } \\
\text { assistance to tasks }\end{array}$ & $\begin{array}{l}\text { Teacher preparing } \\
\text { tech environment }\end{array}$ & $\begin{array}{l}\text { Teacher designing } \\
\text { plan and materials }\end{array}$ \\
\hline $\begin{array}{l}\text { Distributed } \\
\text { Classroom }\end{array}$ & $\begin{array}{l}\text { Getting presentations, } \\
\text { doing exercice }\end{array}$ & $\begin{array}{l}\text { Teacher presenting } \\
\text { information }\end{array}$ & $\begin{array}{l}\text { Teacher answering } \\
\text { questions }\end{array}$ & $\begin{array}{l}\text { Teacher preparing } \\
\text { tech environment }\end{array}$ & $\begin{array}{l}\text { Teacher designing } \\
\text { plan and materials }\end{array}$ \\
\hline $\begin{array}{l}\text { Web/MM } \\
\text { self-training }\end{array}$ & $\begin{array}{l}\text { Navigating through } \\
\text { MM content }\end{array}$ & $\begin{array}{l}\text { Sites and MM } \\
\text { materials }\end{array}$ & $\begin{array}{l}\text { Help components, } \\
\text { FAQs }\end{array}$ & $\begin{array}{l}\text { Manager organizing } \\
\text { events and support }\end{array}$ & $\begin{array}{l}\text { Team designing } \\
\text { web sites or MM }\end{array}$ \\
\hline $\begin{array}{l}\text { On-line } \\
\text { training }\end{array}$ & $\begin{array}{l}\text { Getting information } \\
\text { Interacting in a forum }\end{array}$ & $\begin{array}{l}\text { Teacher refering to } \\
\text { learning material }\end{array}$ & Animating forums & $\begin{array}{l}\text { Manager organizing } \\
\text { events and support }\end{array}$ & $\begin{array}{l}\text { Teacher designing } \\
\text { activities }\end{array}$ \\
\hline $\begin{array}{l}\text { Community } \\
\text { of practice }\end{array}$ & $\begin{array}{l}\text { Exchanging expertise } \\
\text { and know-how }\end{array}$ & $\begin{array}{l}\text { The learners and } \\
\text { some documents }\end{array}$ & Group animator & $\begin{array}{l}\text { Manager organizes } \\
\text { events and support }\end{array}$ & $\begin{array}{l}\text { Designing process } \\
\text { based scenarios }\end{array}$ \\
\hline $\begin{array}{l}\text { Performance } \\
\text { support }\end{array}$ & $\begin{array}{l}\text { Solving situated real- } \\
\text { life problems }\end{array}$ & $\begin{array}{l}\text { Organization's } \\
\text { data, documents }\end{array}$ & $\begin{array}{l}\text { Intelligent help } \\
\text { systems }\end{array}$ & $\begin{array}{l}\text { Manager supervises } \\
\text { learners }\end{array}$ & $\begin{array}{l}\text { Designing process } \\
\text { based scenarios }\end{array}$ \\
\hline
\end{tabular}

Table 2 - Actors role in six typical delivery models

\footnotetext{
${ }^{4}$ The letters on the links have the following meaning. An R link between an actor, represented as an hexagon, and a process the process represented as an oval, means that the actor rules the process. An I/P link between a resource represented as a rectangle, and a process either means that the resource is produced by the process or is an input to the process. An S link means that a classe of actors is a sub-class of a larger class. These conventions follow those of the MOT knowledge modeling technique [Paquette, 1996,1998].
} 


\section{The VLC architecture}

It is possible to support any mix of the components of these models through a web-based Virtual Learning Center [Paquette 97a]. In the same program, course or learning event, some modules can be based on hypermedia self-training, others on community of practice, and still others on some form of distributed or high-tech classroom.

For this to happen, we need an open, flexible, extensible and interoperable architecture. As shown on figure 2, the Explor@ conceptual architecture has three levels.

At the bottom level, plurimedia learning materials are selected, adapted, digitized or constructed to support content delivery in a subject matter. Then the materials are integrated in a web site giving access to a network of activities, resources and production to be made.

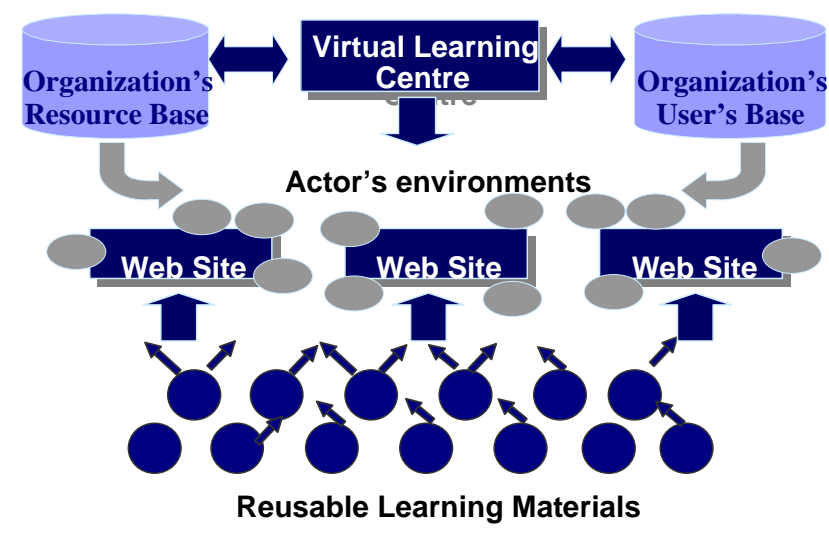

Figure 3 - Explor @'s three level architecture

It is at this second level that the pedagogical strategy will be implemented. For example a simulation of a business process car be integrated in a course in administration, but the same simulation can also be used as an example of material to be analyzed in a course for trainers. The learning scenario implemented in the web site is the component that will tell how the content in the learning materials will be used for learning.

Finally, at the upper level, the designer will add to the course web site one or more telelearning environments for each main actor in the training delivery process. This environment will group resources for self-management of activities, information search and consultation, production of new content (home work), collaboration between learners or trainers and assistance in the form of guides, FAQs, resource persons or intelligent agents.

Figure 4 gives a concrete view of what happens at delivery time. ${ }^{5}$ From an organization's portal the user moves to the VLC home page and provides his identification and password. The system then displays the list of the learning events in which the user has a role in the Virtual Learning Center, together with the role he is authorized to play in each. When he chooses one of these events, two interrelated windows are displayed: the learning event web site and the Explor@window giving access to an environment.

This environment groups a set of resources according to his role in the web site. As displayed on figure 4, a resource can be any tool, multimedia document, or support service to the users according to their roles in the learning event. Here a learner can get access to a calendar and a progress report for the management of her activities, look at a videostreamed information source, collaborate with team mates through desktop videoconferencing, and produce a knowledge model as part of the course assignment.

These roles would have been described thoroughly by the designers and the resources chosen accordingly. The example in figure 4 shows that we are in an hybrid delivery model combining hypermedia self-training with on-line training and community of practice activities. The resources have been chosen for a typical learner from a description of the learning scenarios, the activities and the input resources, and the productions the learner has to make according to the assignments in the activities. A similar analysis would have been made for the trainer and the other actors to enable designers to build their environments.

We will discuss how we propose to do this in the next sections by using an instructional engineering method as a guide to support decision making.

\footnotetext{
${ }^{5}$ Part of this course within the Explor@ environment can be consulted at though LICEF's or the author's web site http://www.licef.teluq.uquebec.ca or http://www.licef.teluq.uquebec.ca/gp
} 


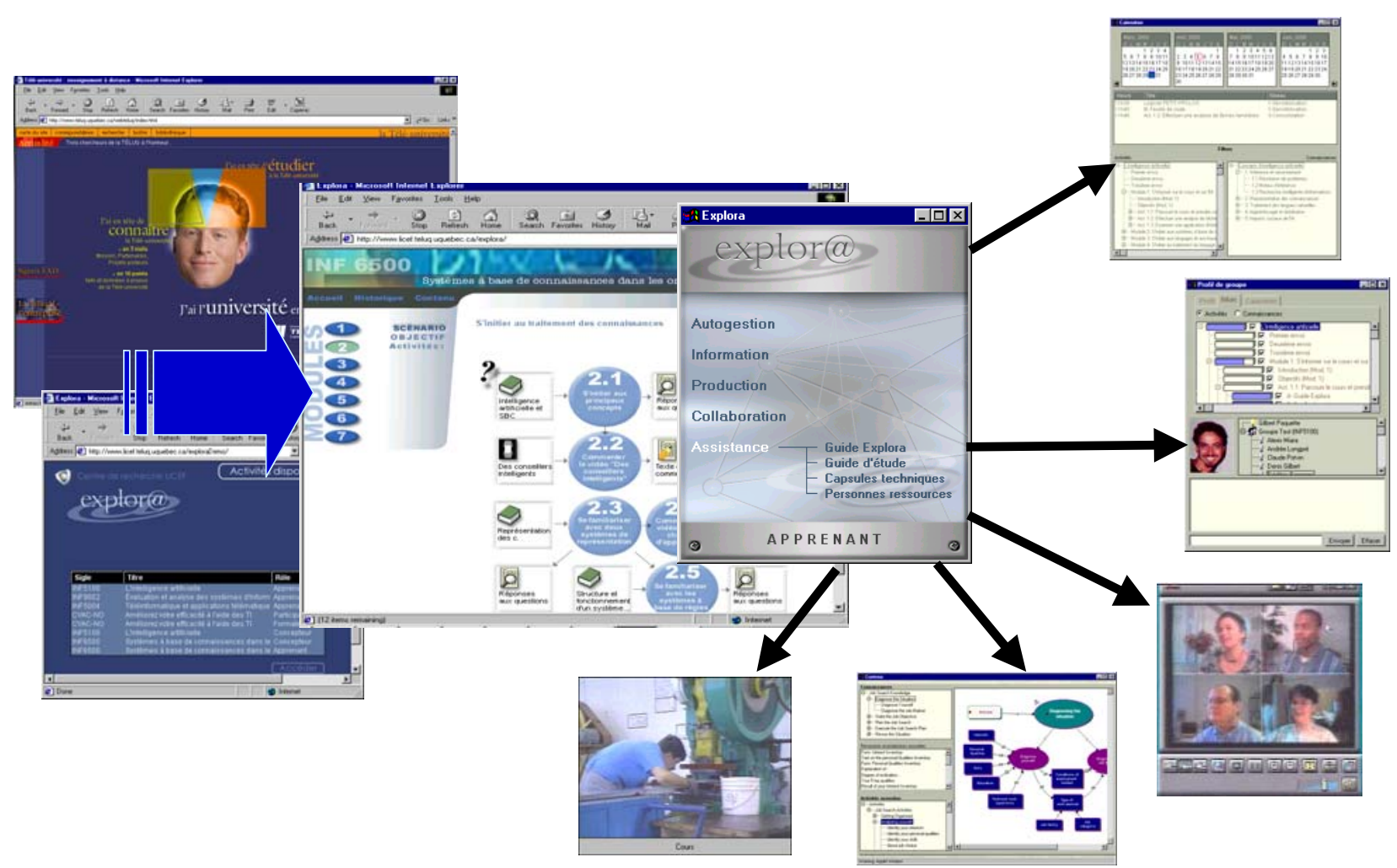

Figure 4 - A course website and the resources in an actor's environment

\section{Interaction spaces and resources}

The resources are distributed in interaction spaces. Each space in concerned with certain types of interactions: selfmanagement of the telearning system, interaction with information sources and production tools, collaboration with other learners or similar actors and assistance from other types of actors such as trainers, informers, managers or designers.

On figure 4, in the Explor@ window for an actor, we can see a distribution of resources into five spaces: selfmanagement, information, production, collaboration and assistance. Other ways to distribute resources in an environment can be implemented in Explor@, but this one is based on our VCL model.

Figure 5 shows the five theoretical actors and their interactions, centered on the interactions in which the learner is involved while learning, at delivery time

- The interactions between learner and designer are those where the learner interacts with the learning environment into which the designer has in a way "mediated" himself by creating it. Here, the learner is preoccupied with the self-management of the learning activities, of their input resources and of the products he has to build..

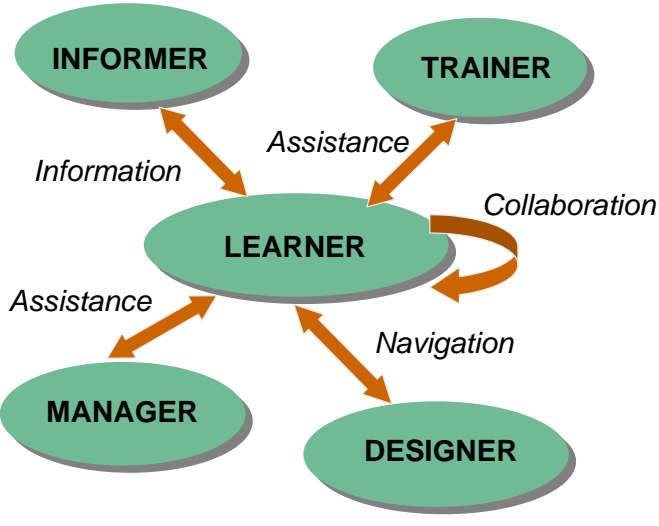

Figure 5 - Actors and interaction spaces 
- The interactions between learner and informer are those where the learner, individually, consults the information made available by the informer, and process them in the production space to produce certain results while building personal knowledge. These lead to the information and to the production interaction spaces.

- The interactions between learners are those enacting different forms of collaboration or cooperation between them for team work, group discussion, collaborative problem solving, etc.

- The interactions between learner and trainers or managers concern the assistance provided in the system to the learner on both the pedagogical (from the trainer) and the management (from the manager) dimensions.

Different actors need different points of view on the host system. For example, in the information space, a learner will need input resources such as a list of related web sites, videos from a server or other learning materials. In the same information space, a trainer will need traces of the learners activities for diagnosis, information on the group of learners and on learner productions and annotation tools to identify and organize information for assistance. Table 3 presents the set of resources made by the author for a learner environment in a course on Artificial Intelligence at Télé-université.

\begin{tabular}{|c|c|c|c|}
\hline $\begin{array}{l}\text { INTERACTION } \\
\text { SPACE }\end{array}$ & RESOURCE & TYPE & DESCRIPTION \\
\hline \multirow{5}{*}{$\begin{array}{l}\text { Self-management } \\
\text { resources }\end{array}$} & Personal Profile & Java & Personal information accessible to all \\
\hline & Progress status & Java & Bar graph displaying progress levels \\
\hline & Calendar of events & Java & Dates where activities were looked upon \\
\hline & Course schedule & HTML & Gantt distribution of activities \\
\hline & Evaluation & HTML & Suggestions and course evaluation by learners \\
\hline \multirow{4}{*}{$\begin{array}{l}\text { Information } \\
\text { resources }\end{array}$} & Texts & HTML & Access to texts to be consulted or produced \\
\hline & Videos & HTML & Access to video streaming \\
\hline & Webography & HTML & Access to interesting web sites \\
\hline & Search engines & HTML & To search for other web sites \\
\hline \multirow{4}{*}{$\begin{array}{l}\text { Production } \\
\text { resources }\end{array}$} & CBTs & EXE & Triggers seven CBTs illustrating IA concepts \\
\hline & Text editor & EXE & Link to a recommended text editor \\
\hline & Knowledge editor & EXE & Link to LICEF'S MOT knowledge editor \\
\hline & Productions made & HTML & Simple file transfer to trainer for production evaluation \\
\hline \multirow{4}{*}{$\begin{array}{l}\text { Collaboration } \\
\text { resources }\end{array}$} & Group profile & Java & Display of other learner's progress and chat \\
\hline & E-mail & EXE & Link to recommended email software \\
\hline & Forums & HTML & Asynchronous teleconferencing system \\
\hline & Showcase & HTML & $\begin{array}{l}\text { Simple upload/download to a server to facilitate the } \\
\text { exchange of productions }\end{array}$ \\
\hline \multirow{4}{*}{$\begin{array}{l}\text { Assistance } \\
\text { resources }\end{array}$} & Explora guide & HTML & Information on use of the environment \\
\hline & Study guide & PDF & Access to a PDF description of the course \\
\hline & Technical help & HTML & A frequently asked questions (FAQ) facility \\
\hline & Resource persons & HTML & $\begin{array}{l}\text { An e-mail list of persons: professor, tutor, manager, } \\
\text { technician, etc. }\end{array}$ \\
\hline
\end{tabular}

Table 3 - Example of of resources distribution in an learner's environment 
These resources are all external to the web site but some of them are connected to it to track actions from the users. There are three types of resources.

- Java applets that we have developed mainly to reflect the user's trace in the web course, to build individual progress reports, group profiles, advisor agents or peer collaboration tools;

- HTML generic services, sometime adapted to the course content; examples of these are course evaluation questionnaires through which learners and trainers will give feedback to designers to improve the course, and also the webography which is a structured list of web sites with comments from the designer.

- Executables files downloaded or resident on the user's workstation, for example CBTs, simulations, or generic software shared by the group so that file exchange is facilitated; this is particularly needed for some communication tools wherein the use of different software will simply not work.

\section{Basis for a design strategy}

We hope to have convinced the reader that there is a large set of interrelated decisions to make when we build a telelearning. What kind of telelearning delivery model or what mix of models? Will we support learners and trainers anywhere, anytime, at any pace? What kind of learning scenarios do we need for this course? Should it be predefined, offer many learning paths or be learner-constructed? Which actors are needed, what are their roles, what resources do they need? What kind of interactivity or collaboration should be included? Will we use multimedia or plurimedia materials? How are we to manage distributed resources? What kind of standards will be used? How can we support interoperability and scalability of the telelearning system? How do we take in account the technological diversity between groups of users within the target population? How can we promote reusability, sustainability and affordability of the web-based learning systems we are building?

\section{Basis for a Design Methodoloy}

To cope with all these decisions, instructional design methodology has a larger role to play than before. We also need a new instructional design methodology that takes in account the full dimension of knowledge intensive telelearning We will use the term "Instructional engineering" to name it, based on the following principles.

- Information system approach. A Telelearning system is an information system, a complex array of software tools, digitized documents and communication services. The artisan-like construction of web based materials is totally insufficient to cope with this inherent complexity. And, so is the use of simplistic authoring tools. Similar to the evolution in software engineering, systematic design processes must support telelearning systems design.

- Knowledge based design. The actual emphasis on knowledge management in organizations leads to the recognition of knowledge and higher order skills as major training goals, as opposed to simple information acquisition. Knowledge engineering is now a well-established methodology rooted in the development of AI and expert systems. Knowledge elicitation, processing and communication and knowledge modeling methods and tools should be at the center of the new instructional design methodology, in relation to the management of knowledge in an organization.

- Multi-agent systems. To be called multi-agent, a system must satisfy four properties. First, the agents, components of the system are situated in an environment. Second, they are autonomous, they control their actions and states. Third, they are adaptive, reacting to change in a flexible way, taking goal-driven initiatives, learning from interactions with other agents. Finally, they are sociable, collaborating and coordinating themselves with users or other software agents [Sycara, 1998]. Multi-agent systems offer a good way to represent a telelearning system at delivery time. This approach corresponds well to the new pedagogical possibilities that web technology can offer. An instructional engineering method should integrate multi-agent modeling to help define the actors and to design environments well adapted to their functions and roles, and also their interactions in the society of agents.

- Plurimedia material and macro-design. A plurimedia material is a set of large grained digitized file to be delivered on different supports: print, CD-ROMs, DVDs, web servers, etc. The emphasis on fine grained closely structured multimedia should decrease as designers observe that there is more videos, textbooks, courseware 
materials out there waiting to be digitized and integrated in more open and flexible scenarios.. Instructional engineering shifts the attention from multimedia micro-design to macro-design and integration of plurimedia materials into the global learning system, to favor reusability and interoperability of learning materials, facilitating also the integration of learning and working activities by the reuse of available corporate documents and tools.

- Constructivist pedagogy based on projects, problem solving and process-centered environments is necessary to promote the acquisition of higher skills \& competencies.

If you propose problems or projects to the learner, he will need to use his analyzing, synthesizing or evaluating skills that will, in turn, orient the search for useful information. At the opposite, a transmission focused pedagogy will embed "just-incase information", wasting a lot of time presenting, whatever the media, masses of information to memorize, understand and sometimes apply later, in a few months or even years. Instructional engineering will put more efforts into building problem based or project based learning scenarios, in order to help develop higher order skills and justin time information.

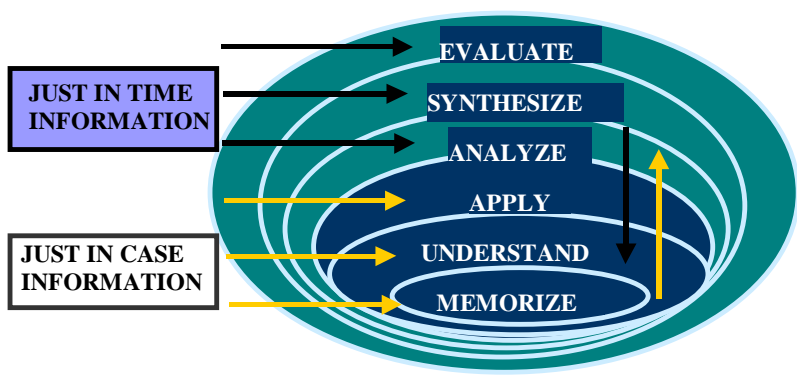

Figure 6 -

Hierarchy of skills and to the role of information

\section{A central construct : learning scenarios}

At the heart of the architecture is the Learning Scenario component that provides many possible work plans to the user. The learning scenario is the common point of reference and the subject of collaboration between the different actors. It is basically a network of learning events (curriculum, courses, modules, activities), learning materials and resources used or produced within these events. As emphasized on figure 2, each actor follows, supports, coaches, manages, designs a certain learning scenario. Each user has his/her own view of the learning scenario, media, and all other resources he/she uses. This way, each document or tool can be parameterized differently by each user. Conversely, each tool and document can accumulate data on its users.

Process-based learning scenarios are the central product of instructional engineering. The approach we propose is based on the fact that specific knowledge in a subject matter and metacognitive skills are being constructed at the same time. A learning unit without an associated skill is like a set of data without any process acting on it.

A learning scenario for a module should be described, whenever possible, as a generic process, corresponding a skill. This skill is to be associated to the knowledge model describing the content of a learning unit or event. In other words, if we want to develop knowledge in a subject matter together with skills like classification, diagnosis, induction or modeling, we should propose classification, diagnosis, induction and modeling problems or projects to the learner.

Then the collaborative activities as well as the information, production and assistance resources will be chosen accordingly. For example, in a classification task, sorting tools in a speadsheet and collaborative classification activities could be embedded in the scenario, together with assistance taking the form of methodological advice to support the classification process.

Figure 7 presents a three-step process in the definition of learning scenario. The example here is a generic task of collaborative writing. This task is part of a virtual conference scenario and it can be used in most knowledge domains.

- In the first step, the activities and the expected learner's productions are described in a graph using the MOT knowledge representation technique [Paquette, 1996]. The activities in the scenario (oval shapes) are linked to the learner's production (rectangular shapes) by input-output (I/P links). Here on figure 7, the learners will search for information and consult writing methods and norms. Then a plan of the document will be sketched and a work plan distributing sections between learners will be built. Finally, the sections will be written by individual learners. Integration of the sections will yield a preliminary text that will be revised and evaluated. 
- In the second step, the actors (hexagons and their roles are described, in relation with each activity. These actors are the team of writers, composed (C link) of a team leader and the other learners, The tutor is also an actor play the role of an evaluation committee or a client who will validate the text at the end. Each of these actors is linked as a control agent to the activities in the scenario by «is-ruling » (R links). Here on figure 7, the team rules the search of information and the distribution of writing assignments, while the project leader rules the sketch of the document plan and the tutor validates the final text and sends its evaluation to the learners.



Figure 7 - Design process of a generic learning scenario 
- In the third step, tools are assigned to the activities in the scenario, taking in account the productions to be made, the learning resources serving as input to the activity and the actors involved. Here on figure 7, a Web browser will be used to search for input information and to consult writing methods and norms. Teleconferencing will be provided to sketch the document plan and distribute the writing assignments. White board and video conferencing tools will be used in the activities where the sections are integrated and, later on, where the text is revised in its final form. Finally, the tutor acting as the client will annotate the text and send its evaluation through Web Email.

A generic scenario, such as this one, can easily be adapted in many ways: rearranging the network of activities, redefining the learner's productions, changing the actor's roles for a new cooperation approach or a completely individual scenario, adding or deleting learning resources or tools to adapt to particular situations.

As we can see, the modeling of learning scenarios is a central issue for the design and delivery of the learning environments built through Explor@. From the scenario, we can design the web site and select the resources to be integrated in the interaction spaces that will constitute a learner, or another user's environment

\section{Outline of an instructional engineering method}

Based on the principles just outlined, we have built in the last eight years a new instructional engineering method called MISA. We have completed a first version of the method in 1994. It has been embedded in a computerized support system for designers called AGD [Paquette et al 1994, 99]. The method was thereafter validated with instructional designers and content experts in nine organizations and was rebuilt according to results and observations gathered during the validations. The actual 4.0 version has been designed in coordination with a new web-based support workbench for instructional engineering called ADISA.

\section{The learning system concept}

The MISA instructional engineering method is based on the concept of a learning system presented on figure 8.

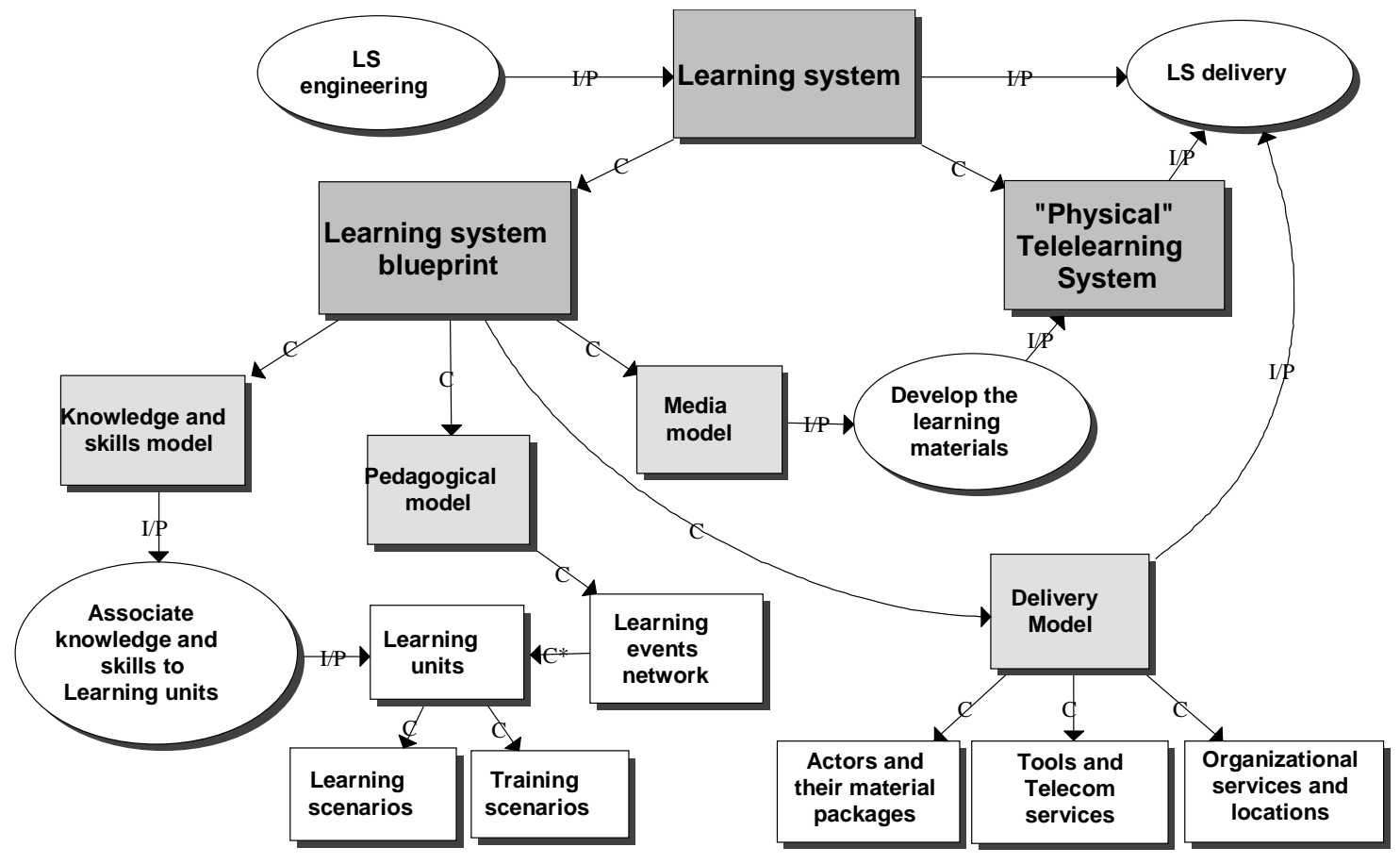

Figure 8 - Learning system concept 


\section{Main tasks of the method}

MISA 4.0 supports the process on figure 8 through 35 main tasks (shown on table 4) and 150 secondary tasks. It results both from top-down research in the field of instructional engineering, and from bottom-up experience acquired through the development of many telelearning courses. Since the method was entirely modelled using MOT, an object-oriented model editor, users may navigate in hypertext graphic mode identifying and completing documentation component graphs and templates, thus building a complete set of specifications of a learning system. The method consists of six well-defined phases. The first digit of a task number identifies the phase. The last five phases unfold along four dimensions: knowledge modelling, instructional modelling, learning materials modelling and delivery modelling. Table 4 shows the content of these four dimensions or axes.

\begin{tabular}{|c|c|}
\hline \multicolumn{2}{|c|}{ Problem definition } \\
\hline 100 Organization's training system & $\begin{array}{l}106 \text { Actual situation } \\
108 \text { Reference documents }\end{array}$ \\
\hline Knowledge Modeling & Instructional Modeling \\
\hline 210 Knowledge modeling principles & 220 Instructional principles \\
\hline 212 Knowledge model & 222 Learning events network \\
\hline 214 Target competencies & 224 Learning units properties \\
\hline \multirow{2}{*}{$\begin{array}{l}310 \text { Learning unit content } \\
410 \text { Learning instrument content }\end{array}$} & 320 Instructional scenarios \\
\hline & 322 Learning activities properties \\
\hline 610 Knowledge and comptency management & $\begin{array}{l}420 \text { Learning instruments properties } \\
620 \text { Actors and group management }\end{array}$ \\
\hline Learning Materials Modeling & Delivery Modeling \\
\hline $\begin{array}{l}230 \text { Media principles } \\
330 \text { Development infrastructure } \\
430 \text { Learning mateirials list }\end{array}$ & $\begin{array}{l}240 \text { Delivery principles } \\
242 \text { Cost-benefit analysis } \\
340 \text { Delivery planning }\end{array}$ \\
\hline 432 Learning materials models & 440 Delivery models \\
\hline $\begin{array}{l}434 \text { Media elements } \\
436 \text { Source documents } \\
630 \text { Learning system and ressource management }\end{array}$ & $\begin{array}{l}442 \text { Actors and user's materials } \\
444 \text { Tools and telecommunication } \\
446 \text { Services and delivery locations } \\
540 \text { Assessment planning } \\
542 \text { Revision decisions log } \\
640 \text { Maintenance and quality management }\end{array}$ \\
\hline
\end{tabular}

Table 4 - Main instructional engineering task in the MISA 4.0 method

In way a similar to software engineering methods, each axis starts with the statement of orientation principles. Each of these sets of principles in 210, 220, 230 and 240 are guidelines that the design team establishes for coordinating its work. They help communication between team members, promote goal directed behavior and help in consistency maintenance throughout the design process.

In each of the four axis, one or more graphic models are built. Knowledge models are the backbone of the method. We build a structured view of the general content (212). Then the content of learning units (310) and learning instruments (410) are all described by knowledge models using different types of knowledge objects and links.

In the instructional axis, process modeling is used to represent the structure of the learning events at the course or program level (222), and also each of the scenarios describing the activities in the learning unit (320). In the learning material axis, we model (432) for example a web site or an hypermedia software, showing the media components, their interrelations through hyperlinks, the media constraints or templates and the source documents to be displayed in the material. Finally, in the delivery axis, we model (440) the actors, their roles, their interactions, their input resources and their productions.

Most of the other tasks in MISA describe properties of the objects contained in the models of the axis where they belong. For example, we describe target competencies (214) related to objects in the knowledge model. Learning activities (322) or learning instruments (420) are properties of the objects in learning scenarios. Source documents (436) describe objects in learning materials models and, finally, tools and telecommunication services (444) describe objects in the delivery models. 


\section{Integrating a Learning Event in the VLC}

Looking back again at figure 3 where we presented the three-level architecture for a VLC, we can see on which MISA specifications do the main component of a VLC rely. There are basically three steps.

1. Building the HyperGuide web site. This step is rather straightforward, based on the models of the learning materials (432). These models and their related property forms provide precise orientations to the development team who can then focus on the ergonomics of the web site and the presentations of the pages. For this they can use any authoring system, web editor or scripting language.

2. Selecting actors and resources. The delivery models are where the multi-agent approach is applied. The selection of the actors and their resources is achieved in parallel to the previous one, based on the MISA delivery models (440) and the associated property forms. At this point, we can decide to have only two actors (learner and trainer) or a full set of 5 or 6 actors based on the VLC model.

Figure 9 shows such a model for the trainer, here labeled as the tutor. Translating this graph in words, we find that the tutor is involved in tutoring roles while the learners are involved in "using the learning system". The tutor should have access to the following support materials: the course web site, a printed manual and VHS videos and some trainer's material. He will communicate through a low band Internet line and work at home. The tutor has four major roles in this learning system. He diagnoses the learners' progress. He acts as a pedagogical coach to the learners. He animates forums. Finally, he evaluates the learners' productions in the course and gives two services: feedback to the learner and information to the administration.

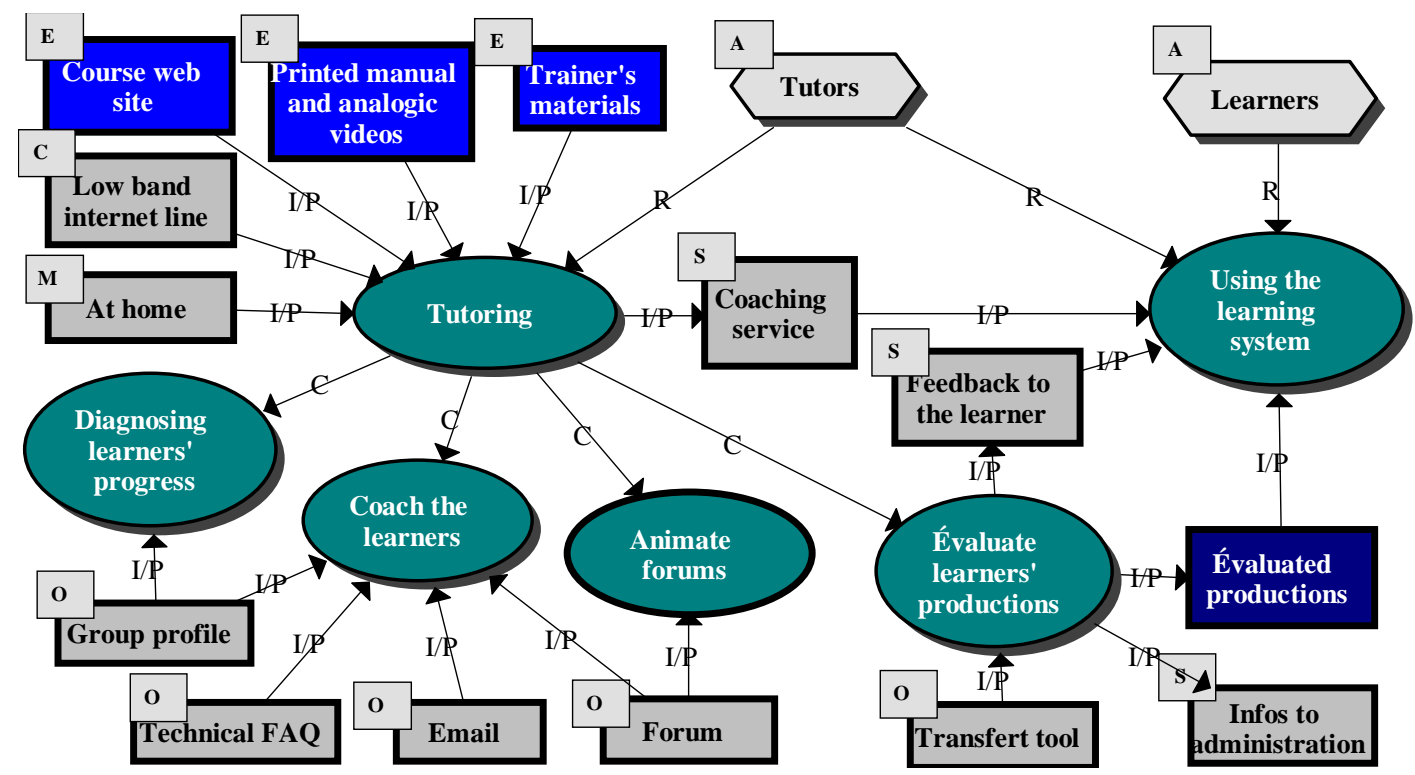

Figure 9 - A delivery model for a trainer actor

To support these roles, the trainer will need tools, labeled $\mathrm{O}$ on the graph. He will need a group profile tool to assess continuously students progress and a tool to maintain a frequently asked questions (FAQ) file. He will use an email software and an asynchronous forum tool to animate and support his group. Finally, he will need transfer tools to get access the learners' productions and send information both to the learner and to the training manager. These tools, materials, communication links and services will form the basis for the trainer's environment for this course in the VLC.

3. The last step consists in linking the course web site and the Explora environments. This step has been presented recently with more details in [Girard et al, 1999]. Essentially, the designer starts from the instructional model and the knowledge model to inform the Explor@system about course structure. Then he uses some of the Explora designer's tools to define progress levels for each learning activity or knowledge unit; these progress levels will be updated dynamically by the Explor@ system during delivery, according to conditions defined by the designer, or by the learner's direct action in a viewing interface. These progress levels constitute a user model employed by the system to give feedback and support to the learner. 


\section{Conclusion}

We hope to have convinced the reader that a full and versatile telelearning system needs to be carefully designed. For this, a certain number of conditions must be met, the most important being the use of an instructional engineering method and some graphical tool to support the design process. Such a method should be rooted in software engineering principles, knowledge modeling and multi-agent representation of the telelearning system at delivery time. 


\section{Aknowledgements}

The author wishes to underline the contribution all the researchers who have participated in the various Virtual Campus and instructional engineering projects at LICEF and have helped these ideas to mature. Also, a special thanks to the Quebec Information Highway Fund, the TeleLearning Network of Centres of Excellence and the Office for Learning Technology (OLT) who have contributed to the funding of these projects.

\section{References}

[Bourdeau et al, 1994] Bourdeau J., Frihida A., Gecsei J., Paquette G. \& de la Teja. Accessing distributed multimedia documents for instructional use, I., in Ottman, T. \& Tomek, I, Educational Multimedia and Hypermedia, 1994. Charlotteville, VA: Association for the Advancement of Computing in Education, 85-91.

[Dufresne et al, 19 99] Dufresne, A., Cosmova, V., LeTran, T., \& Ramstein, C. Explora: An Interface to Support the Learner with Dynamic Graphs and Multimodal Goal Driven Explanations. AIED'99, IOS Press, Maine, 1999.

[Gery, 1997]. Gery G. Granting Three Wishes Through Performance-Centred Design, NATO Communications of the ACM, volume 40, number 7, pp.54-59, 1997.

[Girard et al 1999] Girard J., Paquette G., A. Miara and K. Lundgren.. Intelligent Assistance for Web-based TeleLearning. In S.Lajoie and M. Vivet (Eds), AI in Education - Open Learning Environements, IOS Press, 1999.

[Harasim, L. 1990]. Harasim, L. Online Education: An Environment for Collaboration and Intellectual Amplification. In L. Harasim (Ed.), Online education: Perspectives on a new environment. Praeger Publishers, New York, 1990.

[Henri et Ricciardi-Rigault, 1994] Henri, F., Ricciardi Rigault, C. Collaborative Learning and Computer Conferencing. NATO Advanced Workshop, Grenoble, Sept.. 1993; to be published in T.T. Liao (Ed) Advanced Educational Technology: Research Issues and Future Potential, Springer-Verlag, Berlin, 1994.

[Hiltz 1990] Hiltz, R. Evaluating the Virtual Classroom. In Harasim, L. (ed.) Online education: perspectives on a new environment. Praeger Publishers, New-York. pp. 133-184, 1990.

[Jacobson, 1993] Jacobson I. (1993). Le génie logiciel orienté objet. Paris: Addison-Wesley.

[Paquette et al 99] Paquette G., Aubin C. and Crevier, F. MISA, A Knowledge-based Method for the Engineering of Learning Systems, Journal of Courseware Engineering, vol. 2, August 1999.

[Paquette, 1998] Paquette, G. Meta-knowledge Representation : Application to the Engineering of Telelearning Systems. TLNCE technical report series, Simon-Fraser University, November 1998, 81 pages

[Paquette, 1997a] Paquette, G Virtual Learning Centres for XXIst Century Organisations. In F. Verdejo and G. Davies (eds.). The Virtual Campus, Chapman \& Hall, London. pp. 18-34, 1997.

[Paquette et al, 1997b] Paquette G., Aubin C. and Crevier, F. Design and Implementation of Interactive TeleLearning Scenarios. Proceedings of ICDE'97 (International Council for Distance Education), Penn State University, USA, June 1997.

[Paquette, 1996] G. Paquette. La modélisation par objets typés: une méthode de représentation pour les systèmes d'apprentissage et d'aide a la tâche. Sciences et techniques éducatives , France, avril 1996

[Paquette et al, 1996] Paquette G., Ricciardi-Rigault C., Paquin C., Liégeois S. and Bleicher E. (1996). Developing the Virtual Campus Environment, ED-Media International Conference, Boston, June, 1996.

[Paquette et al, 1995] G. Paquette , C. Ricciardi-Rigault, J. Bourdeau, C. Paquin \& S. Liégeois. Modeling a Virtual Campus Environment for Interactive Distance Learning, ED-Media International Conference, Graatz, Austria, June 1995.

[Paquette et al, 1994] G. Paquette, F.Crevier, C. Aubin. ID Knowledge in a Course Design Workbench. Educationnal Technology, USA, volume 34, n. 9, pp. 50-57, November 1994

[Paquette et al, 1993] Paquette G., Bergeron G., Bourdeau J. The Virtual Classroom revisited. TeleTeaching'93 Proceedings, Trondheim, Norway, August 1993.

[Ricciardi-Rigault et al, 1994] Ricciardi-Rigault, C., Henri, F. Developing Tools for Optimizing the Collaborative Learning Process, Proceedings of the International Distance Education Conference, Penn State University, USA, June.1994.

[Sycara, 1998] Sycara K. P The many faces of Agents, AI Magazine, Summer 1998. 